\title{
Propuestas de adaptación terminológica al español de la estandarización de la terminología del tracto urinario inferior en niños y adolescentes de la ICCS
}

\author{
Consenso de la SINUG y del Grupo Español de Urodinámica.
}

Traducción inicial de Roberto Martínez-García* (aspectos urológicos) y Miguel Mínguez Pérez (aspectos de terminología anorrectal/gastrointestinal). Consensuado en el Congreso XX aniversario de la SINUG en Barcelona:Jara Michael O, Martínez Agulló E, Bustamante Alarma C, García Sastre E, Hualde Alfaro A, Pomar Moya-Prats P, Ramos Roncero C, Rapariz González M, Ravina Pisaca M, Rioja Sanz C, Rodríguez Hernández P, Martínez-García R, Pascual Amorós MA, Pascual Piédrola I, Perales Cabanas L, Rebasa Lull M, Robles E, Zubiaur Líbano C.

Basada en el informe:

Tryggve Nevéus, Alexander von Gontard, Piet Hoebeke, Kelm Hjälmås †, Stuart Bauer, Wendy Bower, Troels Munch Jørgensen, Søren Rittig, Johan Vande Walle, Chung-Kwong Yeung and Jens Christian Djurhuus.

The Standardization of Terminology of Lower Urinary Tract Function in Children

and Adolescents: Report from the Standardization Committee of the International Children's Continence Society.

J Urol Vol. 176, 314-324, July 2006

Actas Urol Esp. 2008;32(4):371-389

\section{RESUMEN}

Objetivos: Adaptar al español la terminología del tracto urinario inferior en el ámbito pediátrico con motivo del informe de la ICCS de 2006

Material y metodología: se han mantenido discusiones en la Reunión de Consenso en conceptos y terminología en la que han participado miembros de Grupos Español de Urodinámica y de la Sociedad Iberoamericana de Neurourología y Uroginecología (SINUG).

Resultados y conclusiones: Se ofrecen las nuevas definiciones y terminología estandarizada en español, que tiene en cuenta los cambios realizados en el ámbito de los adultos y los nuevos resultados en la investigación. Se presentan los términos ingleses (frecuentemente entre paréntesis). Se discuten algunas propuestas (usualmente en las notas al pie).

\section{ABSTRACT}

Aim: Adapt to Spanish the 2006 ICCS standardization of terminology of lower urinary tract function in children and adolescents.

Material and method: Discussions have been held at the Consensus Meeting on terminology and concepts. Members of the Spanish group of urodynamics and of the SINUG (Ibero American Society of Neurourology and Urogynecology) have participated.

Results and conclusions: New definitions and standardized terminology are presented in Spanish. They take into account changes made on the adult scope and the new investigation results. English terms are presented (usually in brackets). Some proposals are discussed (normally in foot notes).

$\mathrm{C}$ omo viene siendo tradicional en sus congresos, el Grupo Español de Urodinámica de la AEU (Asociación española de Urología) y la SINUG (Sociedad Internacional de Neurourología y Uroginecología), convocan a especialistas implicados en el estudio la función del tracto urinario inferior para avanzar en el con- senso de la terminología y conceptos. Con ocasión del XX Congreso Aniversario de la SINUG, organizado por el Dr. Juan Conejero-Sugrañes y que tuvo lugar en Barcelona los días 2 al 5 de Octubre de 2007, urólogos y ginecólogos españoles y latinoamericanos hemos tenido reuniones terminológicas diarias. 
Como corresponde a un aniversario es momento de mirar hacia atrás y así ver nuestra trayectoria. La fundación de la SINUG hace 20 años, en 1987, surgió con una enorme preocupación por la unificación de la terminología y los conceptos. Sólo dos años más tarde ya aparecieron las primeras publicaciones ${ }^{1-4}$ que intentaron mejorar la comunicación entre los hispanohablantes adaptando las tendencias marcadas por las publicaciones en lengua inglesa a nuestra lengua.

El trabajo de adaptación terminológica y conceptual progresó ${ }^{5-11}$ y evolucionó a grupos cada vez mayores, multidisciplinares y de diferentes procedencias, fue institucionalizándose y llegó a ser la norma en todas y cada una de nuestras reuniones, ya se tratara de cursos, talleres o congresos ${ }^{12,13}$. Además trascendió a nuestra revista Urodinámica Aplicada en forma de discusiones abiertas. Obtener el consenso terminológico lo más amplio posible ha sido una obsesión ${ }^{14,15}$, tanto de la SINUG como del Grupo Español de Urodinámica de la AEU, que ha perdurado hasta el último momento a lo largo de estos 20 años.

En este artículo se publica el trabajo realizado antes, en reuniones preparatorias y durante el XX aniversario de la SINUG, de modo que no se trata una mera traducción sino que es el fruto de largas discusiones semánticas y formales. Aunque es fiel al original de la $\mathrm{ICS}^{16}$, se ha añadido comentarios, discrepancias y propuestas en forma de notas al pie de página, algunas ilustraciones aclaratorias y se ha actualizado la información de la tabla 2 (encopresis e incontinencia fecal funcional) a los criterios más actuales de Roma III ( en el artículo de la ICS se tomaba como referencia los criterios de Roma II).

\section{Antecedentes}

El TUI (tracto urinario inferior) en niños es un campo que abunda en confusiones semánticas. Diferentes grupos usan definiciones diferentes para los términos de uso habitual, tales como enuresis, incontinencia, VHA (vejiga hiperactiva), respuesta al tratamiento, etc. A veces los nombres aplicados a anormalidades específicas se aplican de manera intercambiable para denotar disfunción general y viceversa. Esta confusión es parcialmente un reflejo de la evolución de la investigación moderna, que ha cambiado radicalmente nuestros puntos de vista sobre estas anormalidades durante las últimas déca- das, y también del hecho de que los niños son individuos en crecimiento que difieren de los adultos. Muchas definiciones que son adecuadas en adultos son irrelevantes en niños y viceversa. Así, orinarse en la cama y hallazgos como un vaciado incompleto pueden ser normales en los niños que están comenzando a andar y patológicos en los niños en edad escolar. La maduración del sistema nervioso central es un factor importante a considerar cuando se habla de incontinencia en niños pero no tiene ningún sentido en la enfermedad del adulto, mientras que las alteraciones del sistema nervioso central de la población añosa no tienen relevancia en la infancia.

La ICCS (International Children's Continence Society), que es la organización global multidisciplinaria de profesionales relacionados con el TUI (tracto urinario inferior) pediátrico, ha publicado previamente directivas para evitar esta confusión ${ }^{17}$ pero los recientes avances en la investigación de la enuresis y la incontinencia exigen una clarificación y modificación de la terminología. Esta tarea está siendo realizada por el grupo de la ICCS.

Se reconoce y agradece la valiosa contribución de nuestro amigo fallecido el Dr. Kelm Hjälmås, que participó en la preparación preliminar de este documento, y de la ICS (International Continence Society), que creó las directivas para la terminología del trato urinario inferior en adultos ${ }^{18}$. Estamos también agradecidos a la crítica constructiva de otros expertos (Tabla 1).

Tabla 1. Otros expertos

Paul Abrams, David A. Bloom, Richard Butler, Marc Cenaron, Jonathan Evans, Tom de Jong, David Joseph, Ulla Sillén y otros.

\section{Ámbito y uso del documento}

El objetivo de este documento es proporcionar unas directrices firmes e inequívocas para la terminología de la función y disfunción del TUI en la infancia. Aunque se espera que sea útil para el clínico, su uso principal está en el marco de la investigación, donde la adherencia a una terminología (por ejemplo esta terminología) hará más sencilla la comparación de estudios y disminuirá la confusión entre los investigadores. En el futuro, el material presentado a las reuniones de la ICCS exigirá el uso 
de esta terminología y se propone que los grupos que publiquen en este campo incluyan en su texto la frase "Definiciones de acuerdo con los estándares recomendados por la ICCS y consensuados por la SINUG y el Grupo Español de Urodinámica de la AEU excepto cuando se especifique lo contrario", o una frase de significado equivalente.

Destacamos que el presente documento no dice lo que deben hacer los clínicos o investigadores, sino sólo qué términos usar. Las recomendaciones respecto a las buenas prácticas de investigación y tratamiento no son el objetivo de este artículo. La ICCS tiene la intención en un futuro próximo de desarrollar directrices en campos de anormalidades específicas.
En este escrito, la descripción de los sintomas es seguida de las herramientas de estudio clínico, signos, anormalidades y parámetros de tratamiento. A lo largo de este escrito se expone la relevancia de las diferentes entidades en los distintos grupos de edad. La tabla 2 expone la terminología de la función anorrectal porque las funciones del trato urinario inferior y ano-rectal están interrelacionadas y difícilmente se puede hablar de una sin mencionar la otra. Sin embargo, reconocemos que la ICCS no tiene autoridad para indicar cambios en la terminología anorrectal/gastrointestinal y, en concordancia, en la tabla 2 se citan sólo las definiciones existentes. La tabla 3 muestra una lista alfabé-

\section{Tabla 2}

Encopresis e incontinencia fecal funcional

La incontinencia fecal y urinaria a menudo coexisten en diferentes combinaciones. Por lo tanto, es aconsejable centrarse en las enfermedades asociadas (comorbilidades) y describir cualquier tipo de enuresis nocturna, incontinencia urinaria diurna o incontinencia fecal. En otras palabras, un niño puede tener 3 enfermedades y diagnósticos al mismo tiempo y deben nombrarse cada una de ellas. Los términos generales e inespecíficos como síndrome de eliminación se deberían evitar cuando ocurran estos trastornos combinados.

No es el objetivo de este tabla ofrecer una estandarización completa de la terminología importante para la encopresis e incontinencia fecal funcional. Por lo tanto, sólo se ofrecen las definiciones de las enfermedades principales pero no de los sintomas y signos. Las definiciones se presentan según otras especialidades relacionadas con los niños con estos trastornos ${ }^{19}$, tales como gastroenterólogos pediátricos o psiquiatras infantiles.

La incontinencia fecal es un término paraguas que abarca cualquier tipo de deposición de heces en lugares inapropiados, ya sea de causa funcional u orgánica.

La incontinencia anal es un término general que incluye la salida inapropiada de heces o gases, ya sea de causa funcional u orgánica.

La incontinencia fecal orgánica es el resultado de causas neurológicas, estructurales u orgánicas.

La incontinencia fecal funcional puede ser utilizada como sinónimo de encopresis.

\section{Encopresis}

De acuerdo con la CIE- $10^{20}$ y la DSM-IV ${ }^{21}$ la encopresis se define como una expulsión voluntaria o involuntaria de heces en un lugar inapropiado en un niño de 4 años o mayor (o edad mental equivalente) tras haber descartado causas orgánicas. Debe ocurrir al menos una vez al mes durante 6 meses (CIE-10) o 3 meses (DSMIV).

La encopresis primaria denota que el mayor periodo de tiempo sin escapes ha sido menor de 6 meses.

La encopresis secundaria se define como una recidiva tras un periodo sin escapes y sin signos o síntomas de 6 meses o mayor.

En el subtipo encopresis con estreñimiento (sinónimos: encopresis con estreñimiento e incontinencia por rebosamiento (DSM-IV), encopresis por retención e incontinencia fecal funcional por retención (o estreñimiento asociado)) están presentes el estreñimiento y la encopresis.

En el subtipo de encopresis sin estreñimiento (sinónimos: encopresis sin estreñimiento e incontinencia por hiperaflujo o rebosamiento (DSM-IV), incontinencia fecal funcional no retencionista (o no asociada a estreñimiento) o encopresis solitaria) está presente la encopresis pero no el estreñimiento.

El manchado (soiling) es un término confuso y mal definido que no debería ser usado con el objeto de establecer definiciones internacionales de encopresis (CIE-10 y DSM-IV) o incontinencia fecal funcional.

\section{Estreñimiento*}

Existen diferentes definiciones de estreñimiento. No se puede definir sólo por una frecuencia baja del número de deposiciones sino que requiere signos y síntomas adicionales, como defecación dolorosa, masas abdominales palpables, heces compactas palpables durante el tacto rectal, dolor abdominal, hallazgos ultrasonográficos típicos de retención, como diámetros rectales aumentados e impresiones retrovesicales. Típicamente todas las definiciones incluyen como mínimo lo que expresa la North American Society for Pediatric Gastroenterology and Nutrition: "una demora o dificultad en la defecación, presente durante dos o más semanas y suficiente para causar molestias al paciente"22.

Los criterios de Roma II definieron el estreñimiento funcional como "heces duras, como escíbalos o piedras para la mayoría de las heces; heces firmes dos o menos veces por semana; y por la ausencia de alteraciones metabólicas, endocrinológicas o estructurales"23.

Sin embargo el Consenso de París del Childhood Constipation Terminlogy Group amplió esta definición exigiendo sólo la concurrencia de dos o más de las siguientes características durante como mínimo 8 semanas: menos de 3 deposiciones semanales, más de un episodio semanal de incontinencia fecal, presencia de gran cantidad de heces en el recto o detectables mediante la palpación abdominal, deposición de tal cantidad que puede obstruir la taza, observación de posturas de retención y conductas de aplazamiento y/o defecación dolorosa ${ }^{24}$.

La retención fecal funcional que se definía como intentos repetidos de evitar la defecación debido a miedo asociado a la defecación que conducen a un acúmulo de una masa fecal en el recto. Se definió como la expulsión de heces de gran diámetro y posturas de retención durante al menos 12 semanas ${ }^{23}$ pero hoy se ha considera incluido en la definición de estreñimiento crónico ${ }^{24,25}$.

Criterios diagnósticos de estreñimiento funcional según reunión de consenso Roma III:

*Se han transcrito los criterios del Consenso de Roma III por ser más actuales, en lugar de los de Roma II (vigentes en el momento de escribir el artículo original). 


\section{Tabla 2 (Continuación)}

En niños hasta 4 años de edad, debe incluir al menos 2 de los siguientes criterios mantenidos durante 1 mes $^{26 .}$

1. Dos o menos defecaciones por semana.

2. Al menos un episodio semanal de incontinencia de heces, tras la adquisición de la habilidad de contener.

3. Historia de retención excesiva de heces

4. Historia de defecaciones dolorosas o dificultosas.

5. Presencia de una gran masa fecal en recto.

6. Historia de heces de gran diámetro, que incluso pueden obstruir la taza del váter

Los sintomas acompañantes pueden incluir irritabilidad y disminución del apetito y/o saciedad temprana. Estos sintomas desaparecen inmediatamente tras la defecación.

En niños con edad de desarrollo mayores de 4 años (hasta los 18), el estreñimiento funcional (que incluye estreñimiento funcional y retención fecal funcional) debe incluir 2 o más criterios con insuficientes criterios para el diagnóstico del Síndrome del Intestino Irritable (durante al menos una vez por semana durante al menos 2 meses previos al diagnóstico), como en los adultos ${ }^{25}$ :

1. Dos o menos defecaciones por semana.

2. Al menos un episodio de incontinencia fecal por semana

3. Historia de posturas de retención o de retención excesiva voluntaria de heces.

4. Historia de defecaciones dolorosas o dificultosas.

5. Presencia de una gran masa fecal en el recto.

6. Historia de heces de gran diámetro que incluso pueden obstruir la taza del váter.

Sólo el 5\% de todos los casos de estreñimiento son debidos a causas orgánicas y el 95\% son funcionales. Dados los cambios evolutivos en las definiciones, desde un punto de vista de la investigación es importante definir tanto la frecuencia como los síntomas y signos asociados para poder comparar entre diferentes épocas.

Disquezia (funcional) del lactante ${ }^{26}$

Un lactante menor de 6 meses de edad, debe cumplir ambos de los siguientes criterios:

1. Esfuerzo y lloro durante al menos 10 minutos antes de cada defecación exitosa.

2. Ausencia de otros problemas de salud.

El sindrome de rechazo a la taza del váter ocurre en niños que usan el baño para orinar pero se empeñan en usar un pañal para la defecación. La fobia al váter es una fobia aislada en niños que tienen miedo de usar el váter para orinar o defecar.

Tabla 3. Lista alfabética de los términos más usuales definidos en la terminología de la ICCS

Esta lista ni es completa ni detallada pero se espera que sea útil como lista de referencia rápida para los términos que no son raros o autoexplicativos.

Diario miccional: una tabla estándar para ser completada por el niño o familiares, usada para la evaluación de la función vesical y que incluye datos sobre al menos volúmenes miccionales, frecuencia miccional, ingesta líquida, nocturia, enuresis y episodios de incontinencia.

Frecuencia miccional diurna (daytime) disminuida: 3 o menos micciones diurnas.

Frecuencia miccional diurna (daytime) aumentada: 8 o más micciones diurnas.

Hiperactividad del detrusor: la observación en la cistomanometría de contracciones involuntarias del detrusor durante la fase de llenado. Reemplaza al término de inestabilidad vesical.

Disinergia detrusor-esfinter: es la observación cistomanométrica de la contracción miccional del detrusor simultánea a una contracción involuntaria de la uretra. Hipoactividad del detrusor: es la observación cistomanométrica de una contracción de fuerza y/o duración disminuida que resulta en un vaciado vesical prolongado y/o no consecución del vaciado vesical completo.

Micción obstructiva funcional (dysfunctional voiding): es la contracción habitual del esfinter uretral durante la micción observada en mediciones uroflujométricas Enuresis: incontinencia urinaria intermitente durante el sueño, sinónimo de incontinencia nocturna (intermitente). El término se usa independientemente de si existe o no incontinencia diurna u otros sintomas del tracto urinario inferior. Se puede añadir el calificativo nocturna para mayor claridad.

Enuresis monosintomática: enuresis en un niño sin (otros) sintomas del tracto urinario inferior.

Enuresis no monosintomática: enuresis en un niño con (otros) síntomas del tracto urinario inferior, como incontinencia diurna, urgencia, maniobras de retención, etc.

Enuresis primaria: enuresis en un niño que nunca ha estado seco durante un periodo de 6 meses.

Enuresis secundaria: enuresis en un niño que ha estado seco previamente por un periodo de al menos 6 meses.

Volumen miccional máximo esperado en función de la edad, calculado por la fórmula [30 + (edad en años x 30)] en mL y que se usa como estándar para comparaciones. Reemplaza al término capacidad vesical esperada.

Hoja de volumen frecuencia: es una hoja que debe rellenada por el niño o los familiares, usada para la evaluación de la función vesical pero que no incluye todos los datos requeridos en un diario miccional. Ver anteriormente.

Incontinencia continua: goteo continuo de orina, no en porciones discretas, que indica malformación o lesión yatrógena.

Incontinencia intermitente: escape de orina en porciones discretas (con periodos secos entre los escapes (nota del traductor)) durante el día y/o la noche.

Incontinencia nocturna: ver enuresis.

Vejiga hiperactiva: es la alteración que aflige a los pacientes que notan sintomas de urgencia. Reemplaza al término inestabilidad vesical.

Poliuria nocturna: producción de orina nocturna se supera el $130 \%$ del volumen esperado para la capacidad vesical. Ver anteriormente.

Orina residual: Es la orina que queda en la vejiga tras la micción. La orina residual que supera los 5 a 20 mL indica vaciado vesical incompleto.

Vejiga hipoactiva: es la alteración que aflige a los pacientes con frecuencia miccional baja y necesidad de aumentar la presión abdominal para orinar. Reemplaza al término vejiga perezosa.

Incontinencia de urgencia: es la incontinencia en pacientes que tienen urgencia, por ejemplo la incontinencia en niños con vejiga hiperactiva.

Volumen miccional: es el volumen evacuado en una micción y que queda documentado en el diario miccional. Reemplaza al concepto de capacidad vesical.

Volumen miccional máximo: es el mayor volumen miccional y queda documentado en el diario miccional. Reemplaza al concepto de capacidad vesical funcional.

Micción retardada: incontinencia en presencia del uso habitual de maniobras de retención. 
tica breve de las entidades definidas en este documento más frecuentemente usadas. La tabla 4 ofrece una lista de los instrumentos urodinámicos de uso en niños. La tabla 5 muestra los datos que debe incluir y la información que se puede obtener de un diario miccional. La tabla 6 explica las abreviaturas usadas.

\section{Principios básicos}

Durante la elaboración de esta terminología se han aplicado de manera estricta algunos principios básicos sobre los términos a usar:

1) Deben ser descriptivos y no expresar teorías o suposiciones, por mucho que estén bien fundamentadas respecto a la patogenia subyacente.

Tabla 4. Instrumentos urodinámicos en niños

\begin{tabular}{|c|c|c|}
\hline Instrumento & Edad & Datos \\
\hline Diario miccional & Desde los 5 años & $\begin{array}{l}\text { Volumen miccional } \\
\text { Frecuencia miccional } \\
\text { Producción de orina } \\
\text { Frecuencia de sintomas (escapes, etc.) } \\
\text { Otros datos (Tabla 5) }\end{array}$ \\
\hline Flujometría y residuo postmiccional & Desde los 5 años & $\begin{array}{l}\text { Volumen miccional } \\
\text { Forma de la curva } \\
\text { Valor del flujo máximo } \\
\text { Orina residual }\end{array}$ \\
\hline Cistomanometría & Todas las edades & $\begin{array}{l}\text { Presión y actividad del detrusor } \\
\text { Capacidad vesical cistomanométrica } \\
\text { Acomodación } \\
\text { Actividad y competencia esfinteriana } \\
\text { Otros datos (ver la sección específica) }\end{array}$ \\
\hline Observación de las micciones de 4 horas & Lactancia & $\begin{array}{l}\text { Volúmenes miccionales } \\
\text { Frecuencia miccional } \\
\text { Orina residual } \\
\text { Observación de sintomas }\end{array}$ \\
\hline
\end{tabular}

Tabla 5. El diario miccional (datos que debe incluir e información que se puede extraer)

\begin{tabular}{|c|c|c|}
\hline Datos que se deben incluir & Duración de la recogida* & Información que se puede extraer \\
\hline Micciones: hora y volumen & $\begin{array}{l}\text { Mínimo } 48 \text { horas (incluyendo } \\
\text { los volúmenes nocturnos) }\end{array}$ & $\begin{array}{l}\text { Frecuencia miccional } \\
\text { Producción de orina diurna (si no hay incontinencia } \\
\text { urinaria o es de pequeñas pérdidas, en caso contrario } \\
\text { hay que realizar prueba del pañal) } \\
\text { Producción de orina de } 24 \text { horas (si no hay enuresis o se } \\
\text { miden los volúmenes de enuresis) } \\
\text { Volumen miccional medio } \\
\text { Volumen miccional máximo }\end{array}$ \\
\hline Episodios de nocturia & 14 noches & Frecuencia de nocturia \\
\hline Episodios de incontinencia diurna & 14 días & Frecuencia de la incontinencia \\
\hline Volumen de la enuresis $\dagger$ & 7 noches & Presencia o ausencia de poliuria nocturna \\
\hline Otros sintomas del tracto urinario inferior & 14 días & Frecuencia del síntoma \\
\hline $\begin{array}{l}\text { Volumen, horario y tipo de fluidos de la } \\
\text { ingesta líquida } \ddagger\end{array}$ & 48 horas mínimo & $\begin{array}{l}\text { La ingesta líquida en } 24 \text { horas } \\
\mathrm{El} \text { patrón de ingesta líquida }\end{array}$ \\
\hline Horario de acostarse y levantarse $\S$ & 14 días & Tiempo que está acostado \\
\hline Deposiciones & 14 días & Frecuencia de defecación \\
\hline Encopresis * & 14 días & Severidad de la encopresis \\
\hline
\end{tabular}

* Es un compromiso entre lo científicamente validado $27-29$ y lo que se considera práctico con menor riesgo de no cumplimiento y pérdida del paciente del estudio.

† Implica la necesidad de medir el peso de los pañales o ropa de cama y se puede omitir si no es necesaria la medición de la orina producida.

$\ddagger$ Debido a que la producción de orina es igual a la ingesta líquida menos las transpiración insensible.

$\S$ Recomendado pero no obligado

* Se necesita cuando existe encopresis o cualquier sintoma de estreñimiento. 
Tabla 6. Abreviaturas y acrónimos

\begin{tabular}{lll}
\hline $\mathrm{DSM}$ & $=$ & Diagnostic and Statistical manual of Mental Disorder: Manual estadístico y diagnóstico de los desórdenes mentales. \\
$\mathrm{CVE}$ & $=$ & Capacidad vesical estándar (en desuso) \\
$\mathrm{VMMNE}$ & $=$ & Volumen miccional máximo nocturno esperado (del sueño, incluye la primera orina de la mañana) \\
$\mathrm{VMMDE}$ & $=$ & Volumen miccional máximo diurno esperado (de vigilia, excluye la primera orina de la mañana) \\
$\mathrm{EMG}$ & $=$ & Electromiografía \\
ICCS & $=$ & International Children's Continence Society: Sociedad Internacional de Continencia de Niños \\
$\mathrm{CIE}(\mathrm{ICD})$ & $=$ & Clasificación Internacional de Enfermedades (International Classification Diseases) \\
ICS & $=$ & International Continence Society. Sociedad Internacional de Continencia \\
SINUG & $=$ & Sociedad Internacional de Neurourología y Uroginecología \\
AEU & $=$ & Asociación Española de Urología \\
TUI (LUT) & $=$ & Vejiga hiperactiva (Overactive Bladder) \\
VHA (OAB) & $=$
\end{tabular}

Tabla 7. Fórmula del volumen miccional máximo

Nótese que la fórmula no ha sido calculada por un estudio poblacional de niños completamente normales y por ello, la Capacidad Vesical Estándar no debe ser considerada como el volumen miccional máximo normal. Hablando estrictamente, el volumen miccional máximo normal no se conoce. La fórmula se ha elegido con fines prácticos, por su simplicidad y porque es ampliamente usada y conocida.

2) No deben ser ambiguos.

3) Deben ser neutros, libres de prejuicios.

4) Los que se han usado durante muchos años y han llegado a ser familiares (vernáculos) no se pueden descartar sin razones convincentes.

5) Cuando sea posible y razonable, la terminología pediátrica debe seguir la terminología de los adultos, como la estableció la $\mathrm{ICS}^{18}$.

6) Las definiciones deben hacer posible la asignación del término correcto a cada niño sin investigaciones complejas o invasoras. Usualmente una buena historia del caso y un diario miccional deberían ser suficientes.

7) Se debe tener siempre presente el crecimiento y la maduración individual del niño.

8) La división de los pacientes en subgrupos, tales como VHA o micción demorada, es menos importante que la medida o la identificación de las variables relevantes, como la frecuencia miccional diurna. El proceso de dividir a los pacientes en subgrupos crea fronteras artificiales de situaciones biológicas continuas y la elección de los criterios de agrupamiento nos hace desviarnos o predisponernos hacia uno u otro lado. Además, el futuro puede probar que estos criterios son irrelevantes.

\section{SÍNTOMAS}

Los síntomas se han clasificado de acuerdo con su relación con la fase funcional de la vejiga, de vaciado (o micción) o de almacenamiento (o llenado). La duración de los síntomas es irrelevante para el uso de estos términos. La incontinencia se llama incontinencia incluso si sólo ha ocurrido una vez.

\section{Sintomas de llenado}

\section{Frecuencia miccional aumentada o disminuida}

Las estimaciones de la frecuencia miccional son relevantes a partir de los 5 años de edad y tras o desde el logro del control miccional. La observación de que el niño orina constantemente 8 o más veces diarias significa frecuencia miccional diurna aumentada, mientras que 3 o menos micciones diarias se describe como frecuencia (miccional) diurna disminuida. El razonamiento respecto a la elección de estos límites es el siguiente:

1) La observación de que el número de micciones en los niños continentes es entre 3 - 5, y 7 veces al día 30,31 .

2) La experiencia habitual de que los niños con incontinencia $u$ otras enfermedades vesicales que orinan hasta 3 ó 4 veces diarias se benefician de ir al baño más a menudo. Remarcar que en este artículo el término inglés "daytime" se usa en lugar de "diurnal" como sinónimo de diurno. En inglés, "diurnal" es ambiguo ya que en algunos casos se usa como sinónimo de diario, para las 24 horas (día y noche), y otras como el diurno español. 
Los cuidadores pueden ser incapaces de informar sobre la frecuencia miccional hasta que hayan tenido la oportunidad de observar al niño en casa y rellenar un diario miccional, que es una medida importante para valorar objetivamente éste y otros parámetros. La importancia de estas observaciones aumenta cuando se interpreta conjuntamente con la ingesta líquida.

\section{Incontinencia}

La incontinencia (urinaria) significa una pérdida de orina involuntaria. Puede ser continua o intermitente (Fig1).

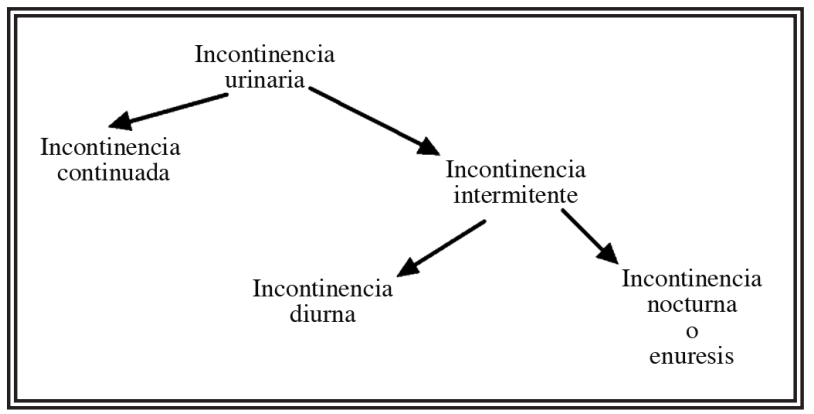

FIGURA 1. Subdivisión de la incontinencia urinaria en niños ${ }^{a}$.

La incontinencia (urinaria) continua significa una pérdida urinaria continua, un fenómeno que se asocia casi exclusivamente a malformaciones congénitas, como uréter ectópico, o lesión yatrógena del esfínter uretral externo. Este término, que reemplaza al término "incontinencia total", se aplica a los niños de todas las edades ya que incluso los lactantes suelen tener un cierto grado de control cortical sobre su micción y están secos entre micciones ${ }^{32}$.

Incontinencia intermitente es la pérdida de orina en episodios que se alternan con intervalos secos. Puede ocurrir durante el día y/o la noche, y se aplica a niños mayores, de cómo mínimo 5 años. Enuresis significa incontinencia intermitente mientras duermen. Remarcar que en contraste con la terminología previa, los términos incontinencia nocturna (intermitente) y enuresis ahora son sinónimos. Así, cualquier tipo de episodio de mojar la cama que ocurre en cantidades discretas durante el sueño se llama enuresis. Además, el síntoma de mojar la cama durante el sueño se llama enuresis o incontinencia nocturna (intermitente) independientemente de la presencia o ausencia de síntomas diurnos concomitantes. La enuresis puede ser llamada enuresis nocturna para clarificar una descripción pero el término "enuresis diurna" es obsoleto y debería ser evitado. Incontinencia diurna es, por supuesto, la incontinencia que ocurre durante el día (no la noche). Los niños con incontinencia combinada diurna y nocturna tienen dos diagnósticos, llamados incontinencia diurna, e incontinencia nocturna o enuresis. Cuando, en inglés, se use el término "diurnal" en lugar de "daytime" se debería clarificar que se refiere sólo a la porción de las 24 horas durante la cual el niño está despierto. Para las subdivisiones en enuresis e incontinencia diurna el lector debe referirse a la sección de alteraciones del TUI.

\section{Urgencia}

Urgencia es el súbito, inesperado e irresistible deseo de orinar. No se puede aplicar antes de conseguir el control miccional o la edad de 5 años, lo que ocurra antes. Otros síntomas de la sensación vesical (sensación de llenado vesical, etc.) no pueden ser extraídos a través de la historia clínica de manera fiable y sólo son importantes en el marco de la cistomanometría (ver más adelante).

\section{Nocturia}

Significa que el niño debe despertarse por la noche para orinar. El sintoma es relevante a partir de la edad de 5 años. La nocturia es frecuente entre los niños en edad escolar ${ }^{33}$ y no es indicativa necesariamente de mal función del TUI. Nótese que el término nocturia no se aplica a los niños que se despiertan por otras razones diferentes de la necesidad de orinar, por ejemplo niños que se despiertan tras un episodio enurético.

\section{Sintomas de vaciado o miccionales}

Que el niño no describa síntomas de vaciado no significa que no existan. Hasta la edad de 7 años, lo que cuente el cuidador o el propio niño puede no ser completamente fiable.

El dolor durante la micción se considerará en el apartado de "otros sintomas".

Los términos usados en la terminología del adulto ${ }^{18}$ de "micción en regadera, dispersa o en sifón" o

ancontinencia diurna quedaría mejor expresado como incontinencia de la vigilia, mientras que incontinencia nocturna, como incontinencia del sueño. 
con chorro dividido que se refieren a las características del chorro urinario son de poca relevancia en la niñez, excepto en caso de estenosis de meato en niños circuncidados.

\section{Retardo miccional (hesitancy)}

Denota dificultad en el inicio de la micción o que el niño tiene que esperar mucho tiempo hasta que comienza la micción. El concepto es relevante a partir de la consecución del control miccional o la edad de 5 años.

\section{Esfuerzo miccional}

Significa que el niño usa la musculatura de la prensa abdominal para iniciar y mantener la micción. Cuando se observa, es relevante a cualquier edad.

\section{Chorro débil}

Se usa cuando se observa la eyección urinaria con poca fuerza y siempre es relevante, desde la lactancia.

\section{Intermitencia o chorro intermitente}

Se aplica cuando el chorro no es continuo sino en porciones discretas. Se puede observar a cualquier edad pero se considera fisiológico hasta la edad de 3 años si no se acompaña de esfuerzo miccional.

\section{Otros sintomas \\ Maniobras de retención}

Son estrategias observables utilizadas para posponer la micción o suprimir la urgencia. El niño puede o no ser completamente consciente del propósito de estas maniobras pero son obvias para los cuidadores. Maniobras usuales son estar de pie de puntillas, cruzar las piernas con fuerza, agacharse sentándose sobre el talón ${ }^{34}$. Son relevantes desde la consecución del control miccional o la edad de 5 años.

\section{Sensación de vaciado incompleto}

El término se explica por sí mismo. No es relevante hasta la adolescencia ya que los niños más jóvenes no suelen reconocer y describir el síntoma.

\section{Goteo postmiccional}

Se usa cuando el niño describe pérdida de orina involuntaria inmediatamente tras la finalización de la micción. Es aplicable desde la consecución del control miccional o la edad de 5 años. El reflujo vaginal (ver más delante) puede producir este síntoma.

\section{Dolor genital o del tracto urinario inferior}

La mayoría de los tipos de dolor del TUI o genital que ocurren en adultos pueden ocurrir en niños teóricamente. Sin embargo, en la práctica pediátrica el dolor en esta área es usualmente inespecífico y difícil de localizar. Así que no se definirá más concretamente.

\section{HERRAMIENTAS DE ESTUDIO CLÍNICO}

Las primeras y principales herramientas para la valoración del TUI en la infancia son: la historia clínica, la observación y el examen físico que no necesitan ser definidos aquí por ser la aptitud central del médico, independientemente del sistema orgánico a valorar. Sin embargo, los diarios miccionales, la clínica miccional (signos y sintomas) y las técnicas urodinámicas requieren una terminología específica que se define en esta sección. La tabla 4 lista estas técnicas. También se usan los cuestionarios, especialmente en los campos de la psiquiatría y psicología infantil.

Para las descripciones de las observaciones urodinámicas en niños se sigue estrictamente la estandarización de la ICS ${ }^{35}$. En este informe se incluyen sólo las particularidades diferenciales de los niños.

\section{El diario miccional}

El registro de micciones y síntomas relacionados con la vejiga bajo condiciones habituales en casa es crucial para la valoración de la función del aparato urinario inferior en niños y es relevante desde la consecución del control miccional o la edad de 5 años. Con este propósito se han realizado distintos protocolos que registran diferente número de días y que han recibido diferentes nombres. De acuerdo con las directivas de la ICS proponemos que en el ámbito de la investigación, un protocolo diagnóstico completo debería llamarse diario miccional e incluir determinados datos (Tabla 5) ${ }^{27-29}$. La información extraíble de los diarios se define en la secciones de signos y sintomas de este artículo. Protocolos menos exhaustivos, como los que se usan habitualmente en el control del tratamiento y seguimiento de los pacientes se deberían etiquetar como hojas de volumen-frecuencia.

La prueba del pañal se refiere a la valoración de las pérdidas de orina debidas a incontinencia diurna mediante medidas repetidas del peso de absorbentes colocados bajo la ropa interior. La prueba es aplicable a niños incontinentes a partir de los 5 
años de edad. Puede ser incluida en el diario miccional pero se usa como prueba independiente en el ámbito pediátrico. Es más relevante la valoración del volumen del escape enurético mediante la determinación del peso del pañal.

\section{Flujometria}

La determinación del flujo miccional y la orina residual (con ultrasonidos) como un examen independiente es, con mucho, el procedimiento más común en la práctica urodinámica pediátrica. En general, los resultados de la flujometría/orina residual deciden si el niño requiere una investigación urodinámica invasora.

En los niños, la determinación de la flujometría/orina residual debería repetirse dos veces en el mismo ámbito en un niño bien hidratado que asegure un volumen miccional razonable en cada micción. Aunque esto exija mucho tiempo, aumenta la precisión exponencialmente. Si las dos mediciones primeras son distintas, puede ser necesaria incluso una tercera. La flujometría es primordial en el diagnóstico en niños tras el aprendizaje del control miccional. Cuando se dispone de electromiografía (EMG) del suelo pelviano, su registro simultáneo le añade valor.

\section{Parámetros flujométricos}

\section{Flujo máximo}

Es la variable más relevante en la valoración del vaciado vesical. Los picos agudos de una curva suelen ser artefactos, así el flujo máximo debe corresponder con un pico de flujo de al menos 2 segundos de duración ${ }^{36}$. En estudios de niños y adultos normales se ha observado una correlación lineal entre el flujo máximo y la raíz cuadrada del volumen miccional $^{37}$. Esto sirve para realizar una evaluación preliminar de los resultados flujométricos: si el cuadrado del flujo máximo $[\mathrm{mL} / \mathrm{s})^{18}$ es igual o excede al volumen miccional en $\mathrm{mL}$, el flujo máximo registrado está probablemente en el rango normal.

\section{Forma de la curva flujométrica}

La forma precisa de la curva flujométrica viene determinada en parte por la contractilidad del detrusor, y en parte por el esfuerzo abdominal y por la resistencia a la salida vesical. En la micción normal la curva es en forma de campana (Fig. 2) y sin picos (lisa o suave). La VHA (vejiga hiperactiva) puede producir una contracción de vaciado explosi-

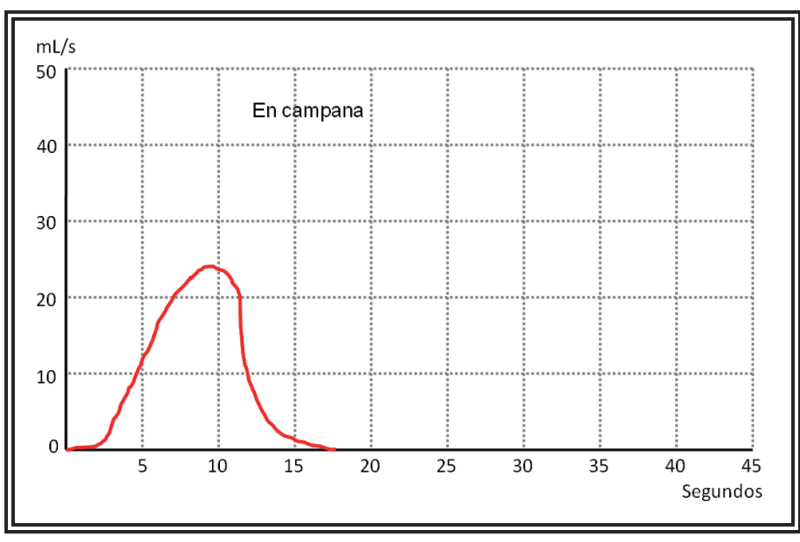

FIGURA 2. Forma flujométrica en campana (bell-shaped).

va que se refleja en la flujometría como una curva de gran amplitud y corta duración, por ejemplo una curva en forma de torre (Fig. 3). Un niño con obstrucción orgánica del tracto de salida, tiene a menudo una curva de baja amplitud e incluso aplanada, llamada en forma de meseta (Fig. 4). Un caso similar puede ser el de una contracción esfinteriana tónica durante el vaciado. Sin embargo, la hiperac-

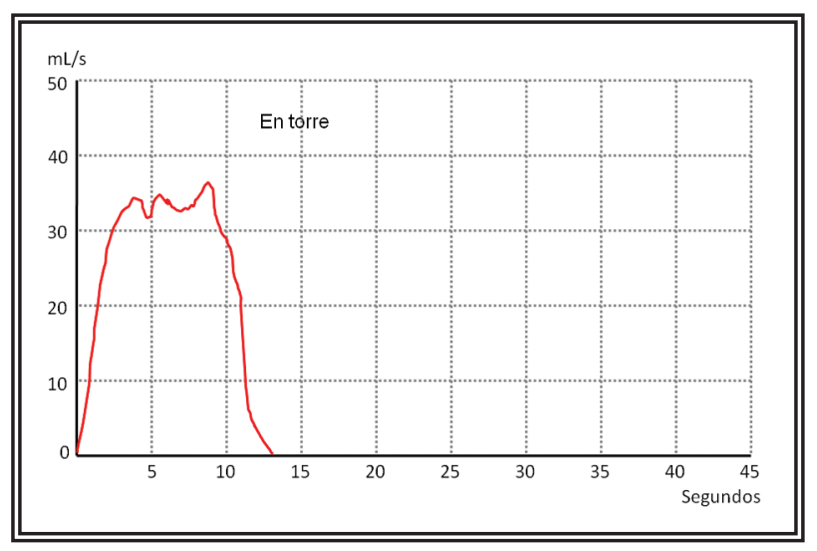

FIGURA 3. Forma flujométrica en torre (tower-shaped).

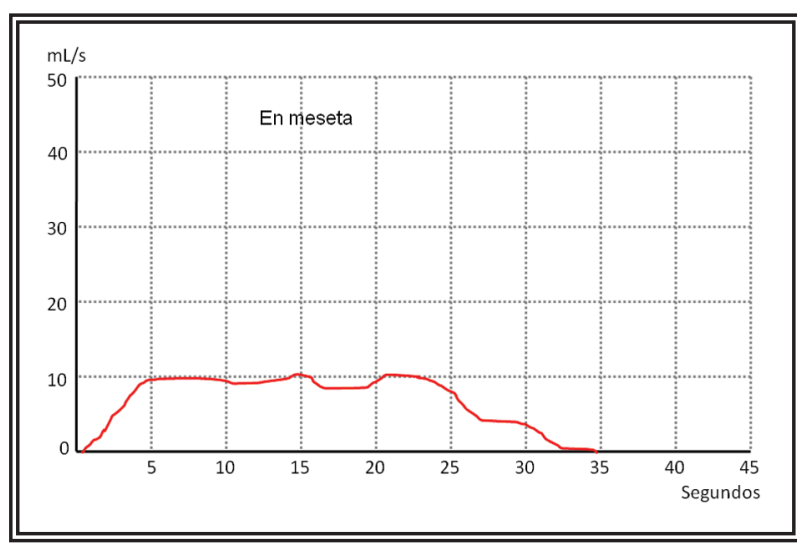

FIGURA 4. Forma flujométrica en meseta (plateau-shaped). 
tividad esfinteriana durante el vaciado suele verse como picos agudos y valles, que se describe como curva irregular, staccato o "en picos" (Fig. 5). Se describe como un flujo continuo pero con fluctuaciones. Para etiquetar un flujo como "en picos" las fluctuaciones (diferencias entre picos y valles) deberían ser mayores que la raíz cuadrada del flujo máximo. Finalmente, en el caso de un detrusor hipoactivo o acontráctil, cuando la musculatura abdominal es la fuerza principal para el vaciado vesical, el patrón flujométrico suele mostrar picos discretos que se corresponden con cada esfuerzo, separados por segmentos sin flujo. Es la llamada curva flujométrica interrumpida o fraccionada (Fig. 6). Para evitar la confusión debida a los múltiples términos que describen la curva flujométrica la ICCS sugiere que se adopte una cierta terminología, que incluya campana, torre, meseta, "en picos" e interrumpido. Estas identificaciones no son una garantía diagnóstica de anormalidad, sino que más bien sirven como una guía de la existencia de una condición específica.

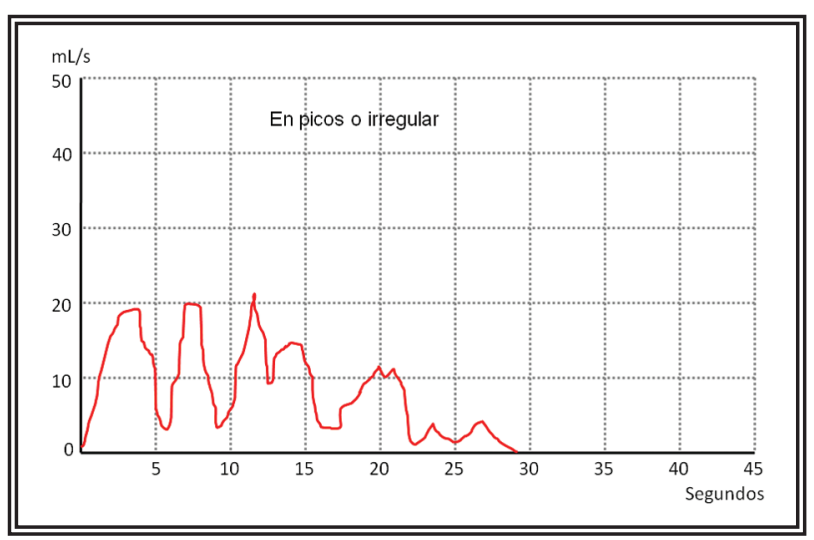

FIGURA 5. Forma flujométrica irregular o en picos (irregular o staccato).

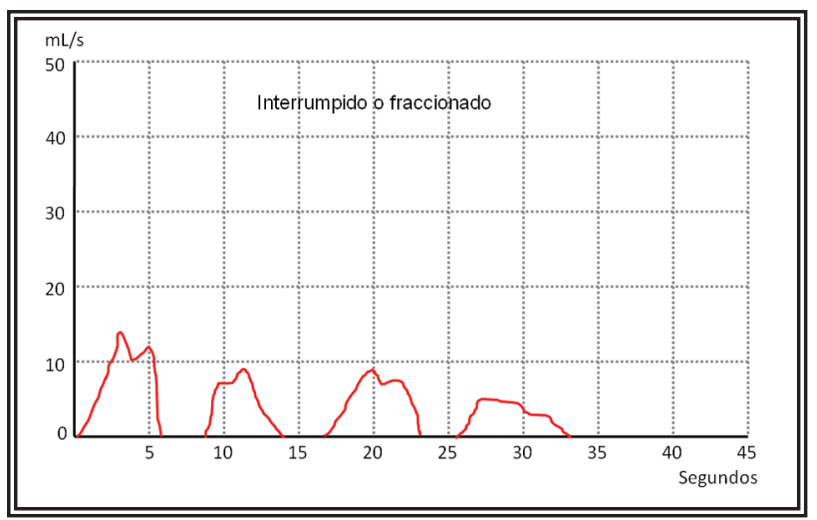

FIGURA 6. Forma de flujometria interrumpida o fraccionada (interrupted or fractionated).

\section{Orina residual postmiccional}

Hoy en día la orina residual se valora mediante ecografía tras la medida flujométrica. En el ámbito diagnóstico se prefiere un equipo ecográfico de tiempo real. El límite mínimo aceptable del 10\% de la capacidad vesical, como a menudo se valora en adultos, no es relevante en lactantes y niños. Los estudios en lactantes sanos y niños que empiezan a andar han mostrado que no vacían su vejiga completamente cada vez que orinan pero sí que lo consiguen al menos una vez en un periodo de observación de 4 horas $^{38}$. Sin embargo, sí que se espera que los niños mayores vacíen su vejiga completamente. $\mathrm{El}$ intervalo de minutos entre el final de la micción y la medición ecográfica da como resultado unos valores normales de hasta $5 \mathrm{~mL}$, que es el valor de orina residual que no se asocia a infección del tracto urinario. El rango entre 5 y $20 \mathrm{~mL}$ podría asociarse con vaciado insuficiente, así que la exploración se debería repetir. Más de $20 \mathrm{~mL}$ de orina residual observada repetidamente indica vaciado anormal o incompleto a condición de que 1) No haya habido una demora mayor de 5 minutos entre el final de la micción y la medición ultrasonográfica y 2) el niño no haya demorado la micción en exceso y llegado a un estado de llenado vesical mayor del normal para el niño o niña. El caso del largo tiempo de demora en la medición, puede compensarse restando de la orina residual, 1 ó $2 \mathrm{~mL}$ por cada minuto que pase de 5 .

\section{INVESTIGACIONES URODINÁMICAS INVASORAS \\ Técnicas urodinámicas invasoras (cistomanométricas)}

Los estudios urodinámicos investigan la función vesical en las fases de llenado y vaciado. Nótese que en el ámbito pediátrico se necesita realizar adaptaciones específicas en la enseñanza del personal, ambiente, apoyo familiar, etc. para hacer el examen del niño más agradable. Si se usa la vía suprapúbica, es necesaria una demora de al menos 5-6 horas entre la inserción del catéter y el registro urodinámico. Si se utiliza un catéter transuretral, tiene que ser de un diámetro tan pequeño como sea posible ya que un catéter grueso puede causar obstrucción del flujo urinario, especialmente en niños pequeños.

La palabra cistomanometría se usa habitualmente para describir únicamente el estudio de la 
fase de llenado del ciclo miccional. La fase de llenado comienza cuando comienza el llenado y finaliza cuando el paciente y el urodinamista lo deciden y se le da permiso para orinar. Esta precisión puede no ser factible en la práctica pediátrica ya que todos los lactantes y muchos niños orinan sin permiso. Así, la distinción entre las fases de llenado y de vaciado sólo se puede realizar a posteriori, cuando se analiza la curva.

De acuerdo con las definiciones de la ICS, la velocidad de llenado fisiológica se define como un valor menor que la máxima predicha para la producción de orina por los riñones, por ejemplo peso corporal en $\mathrm{Kg}$ dividido por 4 y expresado en $\mathrm{mL} / \mathrm{min}^{18}$. Una velocidad de llenado no fisiológica se define como una velocidad superior a la máxima predicha. En los niños sólo deberían usarse velocidades de llenado fisiológicas. Debe mencionarse que estos cálculos no son óptimos ya que una producción de orina de $3600 \mathrm{~mL}$ durante 24 horas en un niño de $10 \mathrm{Kg}$ es claramente no fisiológica en el sentido verdadero de la palabra. Sin embargo, la velocidad de llenado fisiológica representa un valor aceptable de llenado durante una exploración urodinámica estándar. Hjälmås propuso el uso de una velocidad de llenado del 5\% de la cifra de la capacidad vesical esperada expresado en $\mathrm{mL} / \mathrm{min}^{39}$.

El uso de la cistomanometría de llenado natural (ambulatoria) ofrece la velocidad de llenado fisiológica verdadera y es una representación más precisa de la actividad vesical que la cistomanometría tradicional. Esta es la técnica de elección en urodinámica pediátrica cuando el tiempo y el equipamiento están disponibles. Si esto no es factible o práctico, se pueden usar tasas de llenado del 5 al 10\% de la capacidad vesical conocida o predicha.

La función de almacenamiento vesical debería describirse en términos de sensación vesical, actividad del detrusor, acomodación vesical y capacidad vesical.

\section{Sensación vesical durante el llenado cistomanométrico}

Las definiciones de la ICS de la sensación vesical sólo son aplicables a niños mayores y adolescentes. Los lactantes y niños pequeños no son capaces de indicar las diferentes sensaciones. Un fuerte deseo miccional es probablemente la única sensación que muchos niños pueden expresar.
Durante la cistomanometría de llenado la sensación vesical disminuida se define como una sensación disminuida a lo largo de todo el llenado vesical y sensación vesical ausente como ninguna sensación. Las dos condiciones pueden observarse en niños con un detrusor hipoactivo, antiguamente denominado vejiga perezosa. Cuando el llenado excede de la capacidad vesical esperada para su edad (ver más adelante en el apartado de signos) y no se informa ninguna sensación, podemos usar el término de sensación disminuida.

En niños, a veces se observan sensaciones vesicales inespecíficas. Las maniobras de retención (ver más adelante) pueden ser evidenciadas incluso en lactantes por una flexión de los dedos de los pies y movimientos de las piernas. En los niños, cuando el llenado vesical causa dolor, debe detenerse el llenado.

\section{Función del detrusor durante el llenado cistomanométrico}

La función normal del detrusor permite el llenado vesical con ninguna o mínima elevación de la presión y sin contracciones involuntarias fásicas a pesar de maniobras de provocación. Así, en lactantes y niños, cualquier actividad del detrusor observada con anterioridad al vaciado se considera patológica.

La hiperactividad del detrusor, que no debe ser confundida con VHA, es una observación urodinámica caracterizada por la existencia de contracciones involuntarias del detrusor espontáneas o provocadas durante la fase de llenado, que llegan a alcanzar un aumento de la presión del detrusor mayor de $15 \mathrm{~cm}$ de $\mathrm{H}_{2} \mathrm{O}^{\mathbf{b}}$ por encima de la basal. En un adulto con sensación normal, lo más frecuente es que se experimente una sensación de urgencia acompañando a la contracción del detrusor. En las exploraciones de niños la sensación de urgencia en menos fiable. La hiperactividad del detrusor debe ser calificada, cuando sea posible, de acuerdo con la causa en hiperactividad del detrusor de causa neurológica cuando exista una enfermedad neurológica relevante (este término reemplaza al de hiperreflexia) o hiperactividad del detrusor idiopática cuando no existe una causa definida. El término de hiperactividad del detrusor idiopática reemplaza al previo de inestabilidad.

bNuestro grupo de consenso considera que es valorable cualquier aumento de presión cuantificable con expresión clínica. 


\section{Capacidad vesical y acomodación durante el llenado cistomanométrico}

En lactantes y niños, la diferencia entre capacidad cistomanométrica y capacidad cistomanométrica máxima es menos relevante dado las dificultades de los niños en informar sobre su sensación vesical adecuadamente.

La acomodación vesical describe la relación entre el cambio en el volumen vesical y el cambio en la presión del detrusor. Se calcula dividiendo el cambio en el volumen $(\Delta \mathrm{V})$ por el cambio correspondiente en la presión de detrusor ( $\Delta$ pdet $),(C=\Delta V / \Delta$ pdet $)$. Se expresa en $\mathrm{mL} / \mathrm{cm} \mathrm{H}_{2} \mathrm{O}$.

En pediatría, la acomodación vesical es un concepto complicado por diferentes razones.

1) La acomodación cambia normalmente en función del volumen y, por ello, varía con la edad. Por tanto, los valores de la acomodación se deberían relacionar siempre con la capacidad vesical.

2) La presión de detrusor puede afectarse por la velocidad de llenado vesical, y así se prefieren velocidades lentas en niños, especialmente en lactantes.

3) No existen valores de referencia fiables disponibles para la acomodación vesical en la lactancia y niñez. Una regla de andar por casa es que una presión de detrusor de $10 \mathrm{~cm}$ de $\mathrm{H}_{2} \mathrm{O}$ o menor cuando se alcanza la capacidad vesical esperada para su edad sería aceptable (ver más adelante). Debido a que los volúmenes vesicales varían al inicio de la vida de modo que se pasa de unos $30 \mathrm{~mL}$ al nacimiento hasta unos $300 \mathrm{~mL}$ al alcanzar la pubertad, la acomodación tiende a incrementarse con la edad. En los niños jóvenes y lactantes valores de acomodación bajos pueden ser considerados normales. La forma de la curva de llenado es más importante que los valores numéricos de la acomodación vesical, por ejemplo si es lineal o no lineal y, cuando es no lineal, hacia donde se desvía de la linealidad. Debido a estos factores de confusión, se recomienda que las medidas de uso actual se prueben en todas las publicaciones científicas.

\section{Función uretral durante el llenado cistomanométrico}

La función uretral de los niños se valora usualmente mediante EMG del suelo pelviano usando electrodos de superficie o menos usualmente de aguja. Rara vez se mide la presión uretral de cierre. En los centros que se usen medidas de presión, son aplicables las definiciones de la ICS.
La incontinencia por relajación uretral se define como una pérdida debida a relajación uretral en ausencia de aumento de la presión abdominal o hiperactividad del detrusor. Aunque es una condición rara, se ha descrito en niños y antiguamente se llamaba inestabilidad uretral ${ }^{40}$.

La incontinencia urinaria de esfuerzo urodinámica se aprecia durante el llenado cistomanométrico. Se define como pérdida involuntaria de orina durante un aumento de presión abdominal en ausencia de contracción del detrusor. En la actualidad el término preferido es incontinencia urinaria de esfuerzo urodinámica, no incontinencia de esfuerzo genuina. En niños, la incontinencia urinaria de esfuerzo urodinámica es una enfermedad rara, vista casi exclusivamente en algunas niñas con neuropatía y uropatía.

La presión abdominal de escape es la presión intravesical a la cual se produce la pérdida urinaria debido al aumento de presión abdominal en ausencia de contracción del detrusor. La presión de detrusor de escape no valora la influencia de cualquier componente abdominal en el vaciado vesical, tal como esfuerzo, pero incluye la influencia de la contracción del esfínter voluntario durante el vaciado. Estas definiciones son importantes ya que una presión de escape elevada indica que existe riesgo de daño del aparato urinario superior. Se propone que el término presión abdominal de escape se use en lugar de presión de escape de Valsalva, que tendría el mismo significado.

\section{Estudios de presión-flujo: Evaluaciones cistomanométricas durante la fase de vaciado}

Aunque se puede evaluar la relación entre presión y flujo en lactantes y niños, no se suelen realizar debido a su pobre relevancia clínica en este grupo de edades.

La micción normal se consigue por una contracción del detrusor mantenida que conduce a un vaciado vesical completo en un tiempo normal y en ausencia de obstrucción. No es necesario decir que en los niños, antes del aprendizaje del control miccional la contracción no tiene que ser iniciada voluntariamente. Para una magnitud de contracción del detrusor dada, la presión de detrusor registrada depende de la resistencia del tracto de salida. Este concepto puede aplicarse a niños mayores y adolescentes. En los lactantes, las altas presiones de detrusor durante el vaciado pueden ser normales. 
La hipoactividad del detrusor, no confundir con vejiga hipoactiva, es una contracción de fuerza y/o duración disminuidas, que acarrea como consecuencia un vaciado prolongado y/o fracaso en conseguir un vaciado completo en un tiempo de vaciado normal. Un detrusor acontráctil no muestra ninguna contracción durante ningún estudio urodinámico. Las dos condiciones se pueden observar en la clínica. Antiguamente se llamaba vejiga perezosa pero ahora nos referimos a esta entidad como vejiga hipoactiva (ver más adelante).

Nótese que la máxima presión de detrusor durante el vaciado no se corresponde con la presión de detrusor en el momento de flujo máximo. Estos valores son diferentes entre lactantes y niños mayores, y entre hombres y mujeres.

En los lactantes y niños, la función uretral durante el vaciado se suele medir mediante el registro EMG del suelo pelviano usando electrodos de superficie en piel. Este método sólo ofrece una estimación de la función del suelo pelviano y uretral pero suele ser suficiente para el objetivo diagnóstico en el marco pediátrico. Se puede conseguir una mayor precisión funcional usando electrodos de aguja situados en el interior del esfínter y realizando un análisis de potenciales de acción de unidades motoras individuales que se observan en una pantalla de osciloscopio.

La micción obstructiva funcional (dysfunctional voiding) es una entidad urodinámica caracterizada por un flujo intermitente y/o fluctuante debido a contracciones intermitentes involuntarias del músculo estriado del esfínter uretral externo o suelo pelviano durante la micción en individuos neurológicamente normales.

Es un concepto completamente diferente de disfunción miccional (voiding dysfunction), que se ha popularizado como denominación general para denotar cualquier anormalidad relacionada con el llenado y/o el vaciado (ver el prefacio). Este último término no debería usarse. La micción obstructiva funcional se describe en diferentes patologías (ver más adelante). La disinergia detrusor-esfinteriana es un término que se puede utilizar en pacientes con afectación vesical neurógena y consiste en la observación cistomanométrica de una contracción del detrusor de vaciado concurrente con una contracción involuntaria de la uretra y/o musculatura estriada periuretral. Sólo ocasionalmente se llega a interrumpir el flujo miccional. Se debe diferenciar de una contracción involuntaria del detrusor con un aumento simultáneo de la actividad esfinteriana en la EMG, por ejemplo el reflejo guardián normal.

Brevemente, la micción obstructiva funcional es un término aplicado a niños neurológicamente normales que exige para su diagnóstico medidas flujométricas, mientras que disinergia detrusoresfínter se usa sólo en el contexto de niños con neuropatías y requiere urodinámica invasora para su diagnóstico.

\section{Observación miccional de 4 horas}

La observación miccional durante 4 horas es una técnica nueva, científicamente validada y usada para valorar la función vesical en la lactancia ${ }^{41}$. El método implica una observación continua de un lactante que se mueve libremente con medida frecuente ultrasonogáfica del llenado vesical y orina residual tras cada micción. Los volúmenes miccionales se pueden medir también mediante el peso de los pañales.

\section{Signos}

\section{Signos relacionados con el volumen miccional}

La ICS y la ICCS recomiendan el reemplazo del concepto confuso "capacidad vesical" funcional por "volumen miccional" 18 . Esta elección terminológica responde al hecho de que los volúmenes miccionales varían grandemente bajo condiciones normales y reflejan la función vesical mejor que la anatomía (concepto de capacidad). Sin embargo, se necesita además un estándar para comparación y a este estándar se le llama CVE (capacidad vesical estándar). La CVE se estima por la siguiente fórmula [30+(edad en años x 30)] en $\mathrm{mL}^{42,43}$. Esta fórmula es útil hasta la edad de 12 años, tras la cual la CVE es de $390 \mathrm{~mL}$. La CVE se compara con el volumen miccional máximo recogido en un diario miccional (sumándole el volumen de orina residual, si existe y se conoce). El volumen miccional máximo se considera pequeño o grande si se observa menor del $65 \%$ o mayor de $150 \%$ de la CVE, respectivamente (Tabla 7).

\section{Orina residual}

La orina residual es la cantidad de orina que queda en la vejiga inmediatamente tras orinar. El 
término es útil a todas las edades. Como se ha mencionado antes con más detalle, el volumen residual normal es $0 \mathrm{~mL}$, mientras que $20 \mathrm{~mL}$ o más en medidas repetidas es patológico. Valores intermedios representan una zona de interpretación dudosa.

\section{Signos relacionados con la producción de orina}

La cantidad normal de orina producida es difícil de definir en la niñez debido a las grandes variaciones intra e interindividuales y a la ausencia de investigaciones de gran escala ${ }^{44}$. Mientras esperamos estas investigaciones, se propone definir poliuria como la producción de más de 2 L/m2 de superficie corporal en 24 horas de recogida. Esto se puede aplicar a los niños de todas las edades.

La producción de orina nocturna excluye la recogida de la última micción antes de acostarse pero incluye la de la primera micción de la mañana. En niños con enuresis, la orina de las micciones durante el sueño se recoge en los pañales y se mide el cambio en el peso del pañal. La poliuria nocturna es un término relevante principalmente en niños con enuresis $^{45}$. En este grupo de pacientes se define como la producción de orina que excede del 130\% de la CVE para la edad del niño. La filosofía de esta definición es que una alta producción nocturna de orina es sólo relevante si se juzga en relación a la vejiga. De acuerdo con esta definición la poliuria nocturna conduce obviamente a la nocturia o a la enuresis. Sin embargo, debido a la necesaría arbitrariedad de esta definición, se recomienda fuertemente que los grupos que estudian este tema informen la producción de orina nocturna, la CVE o los ratios entre ellos en vez de definir al niño tan sólo como con poliuria o sin poliuria.

Nos damos cuenta de que algunos niños con una producción de orina de 24 horas elevada por razones endocrinológicas o renales pueden no ser correctamente clasificados por la definición anterior de poliuria nocturna si su vejiga se ha acomodado y ha llegado a ser más grande. Por lo tanto, en estos niños la clasificación en poliuria nocturna o diurna tiene poca relevancia clínica.

\section{ENFERMEDADES O ALTERACIONES Enuresis}

Como se mencionó en el apartado de los síntomas, enuresis es sinónimo de incontinencia nocturna intermitente. Esto significa episodios de incontinencia en mientras duerme. Enuresis (o incontinencia nocturna) es un síntoma y una enfermedad (o alteración).

\section{Subgrupos}

Teniendo en cuenta el crecimiento, los niños con enuresis difieren desde el punto de vista de la comorbilidad, respuesta al tratamiento y patogenia, y se ha inventado una plétora de diferentes estrategias de subdivisión de la enuresis ${ }^{46-48}$. Todavía no está claro si estas estrategias pueden mostrar relevancia clínica. Por lo tanto, con las excepciones mencionadas, la ICCS no ofrece directivas de subdivisión.

Existe una amplia evidencia de que los niños que tienen síntomas concomitantes de disfunción ${ }^{\mathbf{c}}$ del TUI difieren de los niños sin dichos sintomas clínica, terapéutica y patogénicamente ${ }^{49}$. Por lo tanto, es esencial en este campo una subdivisión inequívoca y universal en enuresis monosintomática y no monosintomática. La subdivisión previa basada sólo en la presencia o ausencia de incontinencia diurna se considera inadecuada ya que otros síntomas diurnos pueden indicar también una función anómala del TUI. La nueva subdivisión es como sigue. Se recomienda que todos los grupos que publiquen estudios sobre enuresis realicen esta subdivisión en su material y método.

La enuresis en niños sin otros sintomas de TUI (excluida la nocturia) y sin historia de disfunción vesical se define como enuresis monosintomática. Otros niños con enuresis y otros síntomas del TUI se dice que padecen una enuresis no monosintomática. Los síntomas del TUI relevantes para esta definición son frecuencia miccional aumentada/disminuida, incontinencia diurna, urgencia, retardo miccional (hesitancia), esfuerzo, chorro débil, intermitencia, maniobras de retención, sensación de vaciado incompleto, goteo postmiccional y dolor genital o del TUI.

Nótese también que, en contraste con los documentos previos de la $\operatorname{ICCS}^{17}$, la enuresis en un niño

'Los ingleses proponen usar "mal función miccional" (LUT malfunction) en lugar de "disfunción miccional" (voiding dysfunction) para no confundirlo con "dysfunctional voiding" que nosotros traducimos como "micción obstructiva funcional". 
con incontinencia diurna concomitante se sigue llamando enuresis (o incontinencia nocturna), aunque pertenezca a la variedad no monosintomática.

Si la subdivisión se realiza de acuerdo con el inicio de la enuresis, el término secundaria debería reservarse para niños que han tenido un periodo seco previo de al menos 6 meses $^{50}$. En el caso contrario se debe usar el término enuresis primaria.

\section{Alteraciones diurnas}

La clasificación de las alteraciones diurnas ${ }^{\mathbf{d}}$ del TUI, especialmente las alteraciones con la incontinencia diurna como síntoma central, es menos directa que la de la enuresis. La superposición entre las diferentes alteraciones es considerable, los casos limitrofes son frecuentes y el raciocinio patogénico para agrupar complejos de síntomas en enfermedades (o alteraciones) específicas a menudo no se basa completamente en pruebas. Por ejemplo, un niño puede empezar con incontinencia de urgencia, continuar con una micción obstructiva funcional y micción demorada, $\mathrm{y}$ al final terminar con una vejiga hipoactiva.

Para disminuir esta confusión y ofrecer una base para definiciones precisas con una mayor relevancia patogénica y clínica la ICCS aconseja a los investigadores de estos niños valorar y documentar cuatro parámetros en sus pacientes, a saber:

1) Incontinencia (presencia o ausencia y la frecuencia del sintoma)

2) Frecuencia miccional,

3) Volúmenes miccionales y

4) Ingesta líquida.

Esto es más importante que subdividir a los niños en los diferentes síndromes reconocidos y listados más adelante. Obviamente estas alteraciones, incluyendo la incontinencia, son aplicables desde la edad a la que se consiguió el control vesical o 5 años.

\section{Vejiga hiperactiva e incontinencia de urgencia}

Estamos de acuerdo en la práctica actual de la comunidad de urólogos de adultos de evitar el término poco claro de inestabilidad vesical ${ }^{18}$ y reemplazarlo por VHA. El sello o característica específica subjetiva de la VHA es la urgencia y, así, podemos decir que los niños con este síntoma tienen una VHA. La incontinencia a menudo también está presente, así como la frecuencia aumentada, pero estos sintomas no son prerrequisitos necesarios para el uso del término VHA. La razón para no incluir la frecuencia miccional aumentada es que no está completamente claro si tiene algún significado clínico o patogénico, especialmente si no se tiene en cuenta la ingesta líquida. Los niños con VHA usualmente tienen hiperactividad del detrusor pero esta etiqueta no se les puede aplicar sin una evaluación cistomanométrica (ver antes). La incontinencia de urgencia significa simplemente incontinencia con la presencia de urgencia y, así, es un término aplicable a muchos niños con VHA.

\section{Micción retardada}

Los niños con incontinencia diurna cuyos padres y/o cuidadores observan que frecuentemente posponen la micción, a menudo en situaciones específicas, usando maniobras de retención se dice que tienen micción retardada. Esto se asocia a menudo a frecuencia miccional baja y a una sensación de urgencia debida a que la vejiga está completamente llena. Algunos niños han aprendido a restringir la ingesta líquida como método de aumentar los intervalos intermiccionales $\mathrm{y}$ al mismo tiempo disminuir la incontinencia. El razonamiento para delimitar esta entidad se basa en la observación de que estos niños a menudo tienen alguna comorbilidad psicológica o alteraciones de la conducta ${ }^{51}$.

\section{Vejiga hipoactiva}

La antigua entidad de la vejiga perezosa (adjetivo con significado peyorativo en inglés) se ha reemplazado en la actualidad por el término neutro de vejiga hipoactiva. Este término se reserva para los niños con frecuencia miccional baja y una necesidad de aumentar la presión abdominal para iniciar, mantener o completar la micción, por ejemplo haciendo fuerza. Los niños suelen presentar un chorro miccional con patrón interrumpido en las determinaciones flujométricas y se suelen calificar con el término de detrusor hipoactivo si se examinan con una prueba urodinámica invasora.

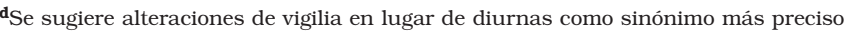




\section{Micción obstructiva funcional (dysfunctional Voiding)}

El niño con micción obstructiva funcionale habitualmente contrae el esfinter uretral durante la micción. El término no se puede aplicar a no ser que en flujometrías repetidas se muestren curvas con un patrón "en picos" o se realice un estudio urodinámico invasor. Nótese que el término describe una disfunción sólo durante la fase de vaciado. No dice nada sobre la fase de llenado. El uso de esta expresión para denotar cualquier tipo de función del TUI alterada $^{52}$ conduce a confusión y se desaconseja con fuerza. La micción obstructiva funcional significa alteración funcional durante el vaciado. Por supuesto que en un niño puede ocurrir una micción obstructiva funcional junto a otros síntomas en la fase de llenado como una incontinencia.

\section{Obstrucción}

Los niños que tienen un obstáculo a salida de la orina durante la micción, ya sea por causas mecánicas o funcionales, fásicas o continuas, se dice que tienen obstrucción del TUI. La obstrucción se caracteriza por una presión de detrusor aumentada junto a un flujo urinario disminuido. Los diferentes tipos de obstrucción del TUI en niños son fáciles de describir y cuantificar mediante técnicas video urodinámicas ${ }^{53}$.

\section{Incontinencia de esfuerzo}

La incontinencia de esfuerzo es la pérdida de pequeñas cantidades de orina con el esfuerzo o ante el aumento de la presión abdominal por diferentes razones. Es rara en niños neurológicamente normales. Debería diferenciarse de la incontinencia de los niños que posponen la micción (micción retardada) y no llegan a tiempo a baño, y de los escapes en niños con VHA en los que las contracciones del detrusor pueden ser provocadas, por ejemplo por un aumento de la presión abdominal. El término incontinencia mixta se aplica a pacientes con una combinación de incontinencia de urgencia e incontinencia de esfuerzo. También es raro en la infancia.

\section{Reflujo vaginal}

Las niñas prepúberes que ya han conseguido el aprendizaje del control miccional y tienen inconti- nencia de pequeñas cantidades de orina, de manera constante, en los 10 minutos tras su micción normal, se dice que tienen reflujo vaginal si no se encuentra otro mecanismo diferente al remansamiento vaginal de orina que explique estas pérdidas.

\section{Incontinencia de la risa}

La incontinencia de la risa es un síndrome raro en el que aparece una micción involuntaria aparentemente completa específicamente durante o tras la risa. La función vesical es normal cuando el niño no está riéndose. Esta alteración debe diferenciarse cuidadosamente de otras situaciones mucho más frecuentes como cuando un niño con VHA, micción retardada o vejiga hipoactiva tiene pérdidas durante un fallo en su concentración, por ejemplo cuando se ríe. El término de incontinencia de la risa no se debería usar en estos casos.

\section{Frecuencia miccional diurna extraordinariamente aumentada}

Este término se aplica a los niños que orinan a menudo y en pequeños volúmenes sólo durante el día. La frecuencia miccional diurna es como mínimo una vez por hora y como media los volúmenes miccionales son menores del 50\% de la CVE, y usualmente mucho menores. La incontinencia no es un ingrediente usual ni necesario en esta alteración y la conducta vesical nocturna es normal para la edad del niño. El término se aplica desde la edad del control vesical diurno o desde los 3 años.

\section{COMORBILIDADES}

No es tarea de la ICCS sugerir definiciones y terminología para áreas fuera del contexto del TUI. Sin embargo, consideramos que es útil listar las enfermedades asociadas que son relevantes e importantes a considerar por los investigadores que estudian el TUI en niños. Las enfermedades asociadas incluyen estreñimiento y encopresis (Tabla 2), infección del tracto urinario, bacteriuria asintomática, reflujo vésico ureteral, alteraciones neuropsiquiátricas (trastorno de déficit de atención-hiperactividad, trastorno de oposición desafiante, etc.) alteraciones del aprendizaje y alteraciones del sueño (apneas del sueño y parasomnias).

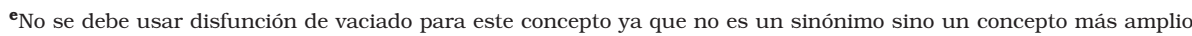




\section{TRATAMIENTO}

\section{Definiciones y métodos de tratamiento}

El tratamiento se refiere en su más amplia acepción a cualquier intervención que pueda ser realizada con la intención de aliviar los síntomas o erradicar el trastorno. El hecho es que el tratamiento ya empieza cuando el cuidador observa por primera vez a un paciente. Incluso partes de un examen, como rellenar un diario miccional o repetir una flujometría, son también partes del tratamiento.

Este documento expresa definiciones y directrices en relación a la terminología sólo. Las recomendaciones para el tratamiento serán objeto de comunicaciones futuras. Se recomienda fuertemente que los autores no usen términos como tratamiento estándar o tratamiento de mantenimiento sin definir qué están incluyendo en estos conceptos.

\section{Tratamiento farmacológico y quirúrgico}

Obviamente significa cualquier tratamiento basado en drogas o cirugía.

\section{Tratamiento de alarma}

El tratamiento de alarma es un tratamiento basado en un aparato que produce una señal sensitiva intensa, usualmente acústica pero no necesariamente, inmediatamente tras la aparición de la incontinencia. Puede ser usado durante el día o la noche, aunque lo último es lo usual.

\section{Uroterapia (urotherapy) (NUEVO)}

Uroterapia, incluida en los trabajos españoles hasta la fecha como "otros tratamientos urológicos", significa un tratamiento del TUI no farmacológico ni quirúrgico. Así, es sinónimo de tratamiento conservador (no farmacológico) o rehabilitador del TUI, que se usa frecuentemente en el ámbito del los adultos ${ }^{18}$. Abarca un amplio campo, incorpora muchas terapias usadas por la enfermería urológica y otros profesionales de la salud. Este abordaje conservador y las terapias anteriormente mencionadas no son mutuamente excluyentes. La uroterapia se puede dividir en terapia estándar e intervenciones específicas:

La terapia estándar no es intervencionista e incluye algunos componentes, a saber:

1) Información y desmitificación, que es la explicación sobre el funcionamiento normal del TUI y de las particularidades que afectan al cada niño en particular.
2) Instrucciones sobre qué hacer sobre el tema, por ejemplo regular los hábitos miccionales, posturas miccionales saludables, evitar las maniobras de retención, etc.

3) Consejos sobre estilo de vida en relación a la ingesta líquida, la prevención del estreñimiento, etc.

4) Documentación de los síntomas y hábitos miccionales usando diarios miccionales o tablas de volumen-frecuencia, $\mathrm{y}$

5) Apoyo y estímulo del cuidador a través del seguimiento regular.

Las intervenciones específicas en al ámbito uroterapéutico se definen en la misma línea que las publicadas por la ICS ${ }^{18}$. Así, aquí sólo se mencionan de pasada. Incluyen varias formas de entrenamiento del suelo pelviano, biofeedback, estimulación eléctrica y cateterismo.

La uroterapia puede incluir elementos de terapia conductual cognitiva, un tipo de psicoterapia que incluye un amplio grupo de técnicas de modificación de la conducta y cognitiva. Sin embargo, el término de terapia conductual cognitiva no debería usarse de forma indiscriminada y sin definir qué técnicas se están usando.

\section{Definiciones de resultados del tratamiento}

En la situación clínica, el niño y la familia afectados son obviamente los únicos que pueden decidir los criterios apropiados del éxito del tratamiento. Sin embargo, en el ámbito de la investigación se necesitan unos estándares uniformes, de manera que se puedan comparar entre sí los estudios y las opciones terapéuticas. El único objetivo de este documento es facilitar la comparación entre los estudios futuros. Para discusiones en mayor profundidad de los parámetros de éxito y de resultados del tratamiento se pueden consultar otros textos ${ }^{19,54}$.

Los investigadores deberían reconocer tres principios básicos:

1) La valoración de los resultados del tratamiento debería basarse en la documentación de la situación basal pretratamiento de la frecuencia de los síntomas.

2) Se debería mostrar la frecuencia real de los síntomas basal y con tratamiento. Esto da mayor información que el agrupamiento de los niños en respondedores y no respondedores. 
3) Se debería clarificar la diferente respuesta durante y tras el cese del tratamiento. Este último parámetro puede a veces reflejar la curación pero el primero nunca.

Cuando por motivos de comparación, los niños se deban agrupar en subgrupos de diferentes grados de respuesta al tratamiento, el agrupamiento se debería realizar como sigue. Los porcentajes deben reflejar la disminución en la frecuencia de los síntomas, por ejemplo una disminución en el número de semanal de noches mojadas.

\section{Éxito inicialf}

La no respuesta se define como $0 \%$ al $49 \%$ de disminución, respuesta parcial se define como una disminución entre el 50\% y el $89 \%$, respuesta se define como una disminución en un 90\% o más y respuesta completa se define como el 100\% de disminución o menos de 1 síntoma mensual.

\section{Éxito a largo plazo}

La recaída se define como la recurrencia de más de un síntoma mensual, éxito continuado se define como ausencia de recaída en 6 meses tras la interrupción del tratamiento y éxito completo se define como la ausencia de recaída a los dos años tras la interrupción del tratamiento.

\section{REFERENCIAS}

1. Castro-Díaz D, Martínez-Agulló E, Conejero-Sugrañes J. Propuesta de terminología de la función del tracto urinario y vaciado vesical: 1. Fase de llenado y vaciado vesical. Urodinámica Aplicada 1989;3(1):39-44.

2. Castro-Díaz D, Conejero-Sugrañes J, Martínez-Agulló E. Propuesta de terminología de la función del tracto urinario y vaciado vesical: 2. Clasificación de la disfunción del tracto urinario inferior. Urodinámica Aplicada 1989;3(2):65-8.

3. Castro-Díaz D, Martínez-Agulló E, Conejero-Sugrañes J. Propuesta terminológica de la función del tracto urinario. En: Martínez-Agulló E, editor. Incontinencia Urinaria. Conceptos actuales. $1^{\text {a }}$ ed. Alzira (Valencia): Graficuatre; 1990. p. 737-754.

4. Conejero-Sugrañes J, Martínez-Agulló E, Garriga i Calatayud J. Definición, conceptos y terminología. En: Ministerio de Sanidad y Consumo.Dirección General de Farmacia y Productos Sanitarios., editor. Libro blanco sobre la incontinencia urinaria en España. Madrid: Ministerio de Sanidad y Consumo; 1991. p. 7-14.

5. Castro-Díaz D, Martínez-Agulló E, Conejero-Sugrañes J. Terminología de la función del tracto urinario: llenado. Urodinámica Aplicada. 1999;12(1):43-48.
6. Castro-Díaz D, Conejero-Sugrañes J, Martínez-Agulló E. Clasificación de la disfunción del tracto urinario inferior Urodinámica Aplicada. 1999;12(1):49-53.

7. Martínez-García R, Martínez-Agulló E. Estudios pronósticos en pacientes con disfunción del tramo urinario inferior. Principios generales. Traducción y homologación conceptual del trabajo del Comité de estandarización de Terminología de la Sociedad Internacional de Continencia (ICS) (presidente, Anders Mattiasson). Urodinámica Aplicada. 1999;12(1):28-32.

8. Del Campo Rodríguez M, Batista Miranda JE, Arañó Bertran P. Estandarización de terminología sobre la función del tramo urinario inferior: estudios de presión-flujo, resistencia uretral y obstrucción uretral.Sociedad Internacional de Continencia (ICS) Subcomité de Estandarización de Terminología de Estudios de Presión-Flujo, coordinado por Anders Mattiasson. Propuesta de versión en español. Urodinámica Aplicada. 1999; 12(1):22-7.

9. Fernández-Ajubita H. Estandarización de la terminología de prolapso pélvico y la disfunción del suelo de la pelvis en la mujer.Propuesta de traducción al español. Urodinámica Aplicada. 1999;12(1):14-21.

10. Villar Marín A, San José Manso L, Ramírez Fernández J, Salinas Casado J. Estandarización de la monitorización urodinámica ambulatoria: informe del subcomité de la Sociedad Internacional de Continencia para los estudios urodinámicos ambulatorios. Urodinámica Aplicada. 2001;14(2):98-102.

11. San José Manso L, Villar Marín A, Ramírez Fernández J, Salinas Casado J. Estandarización terminológica de la hidrodinámica del tracto urinario superior. Sociedad Internacional para la Dinamia del Tracto Urinario Superior, Subcomité de estandarización de Terminología de la ICS. Traduccion al español. Urodinámica Aplicada. 2001;14(3):207-211.

12. Grupo español de Urodinámica de la AEU, SINUG. Estandarización de la terminología de la función del tracto urinario inferior: informe de estandarización del sub-comité de la Sociedad Internacional de Continencia. Propuestas de traducción y homologación conceptual. Urodinámica Aplicada. 2002; 15(4):283-298.

13. Martínez-García R, Ruiz-Cerdá JL, Arlandis-Guzman S Conejero-Sugrañes J, Martínez-Agulló E. Terminología y conceptos de la función del tracto urianrio inferior (Editorial). Urodinámica Aplicada. 2002;15(4):281-282.

14. Grupo Español de Urodinámica y SNUG. Consenso sobre terminología y conceptos de la función del tracto urinario inferior Actas Urol Esp. 2005;29(1):16-30.

15. Martínez-Agulló E. Terminología de la función del tracto urinario inferior (editorial). Actas Urol Esp. 2005;29(1):5-7.

16. Neveus T, von GA, Hoebeke P, Hjalmas K, Bauer S, Bower W, et al. The standardization of terminology of lower urinary tract function in children and adolescents: report from the Standardisation Committee of the International Children's Continence Society. J Urol. 2006;176(1):314-324.

17. Norgaard JP, van Gool JD, Hjalmas K, Djurhuus JC, Hellstrom AL. Standardization and definitions in lower urinary tract dysfunction in children. International Children's Continence Society. Br J Urol. 1998;81 Suppl 3:1-16.

18. Abrams P, Cardozo L, Fall M, Griffiths D, Rosier P, Ulmsten U, et al. The standardisation of terminology of lower urinary tract function: report from the Standardisation Sub-committee of the International Continence Society. Neurourol Urodyn. 2002;21(2):167-178.

f No se refiere a la curación sino la respuesta inicial al tratamiento. Es especialmente importante cuando se habla de un tratamiento farmacológico, ya que está valorando la respuesta farmacológica.

gSon los criterios de curación, el principal objetivo de un tratamiento o intervención terapéutica 
19. Von Gontard A. Enkopresis: Erscheinungsformen - Dianostik Therapie. Stuttgart: Kohlhammer Verlag; 2004.

20. The ICD-10 classification of mental and behavioural disorders: diagnostic criteria for research. Geneva: World Health Organization; 1993.

21. Diagnostic and statistical manual of mental disorders-IV. Washington: American Psychiatric Association; 1994.

22. Baker SS, Liptak GS, Colletti RB, Croffie JM, Di LC, Ector W, et al. Constipation in infants and children: evaluation and treatment. A medical position statement of the North American Society for Pediatric Gastroenterology and Nutrition. J Pediatr Gastroenterol Nutr. 1999;29(5):612-626.

23. Rasquin-Weber A, Hyman PE, Cucchiara S, Fleisher DR, Hyams JS, Milla PJ, et al. Childhood functional gastrointestinal disorders. Gut 1999;45 Suppl 2:II60-II68.

24. Benninga M, Candy DC, Catto-Smith AG, Clayden G, LoeningBaucke V, Di Lorenzo C, et al. The Paris Consensus on Childhood Constipation Terminology (PACCT) Group. J Pediatr Gastroenterol Nutr. 2005;40(3):273-275.

25. Rasquin A, Di Lorenzo C, Forbes D, Guiraldes E, Hyams JS, Staiano A, et al. Childhood functional gastrointestinal disorders: child/adolescent. Gastroenterology. 2006;130(5):1527-1537.

26. Hyman PE, Milla PJ, Benninga MA, Davidson GP, Fleisher DF, Taminiau J. Childhood functional gastrointestinal disorders: neonate/toddler. Gastroenterology. 2006;130(5):1519-1526.

27. Abrams P, Klevmark B. Frequency volume charts: an indispensable part of lower urinary tract assessment. Scand J Urol Nephrol Suppl. 1996;179:47-53.

28. Mattsson S, Lindstrom S. How representative are single frequency-volume charts? Presented at International Children's Continence Symposium 1995. Sydney (Australia).

29. Hansen MN, Rittig S, Siggaard C, Kamperis K, Hvistendahl G, Schaumburg HL, et al. Intra-individual variability in nighttime urine production and functional bladder capacity estimated by home recordings in patients with nocturnal enuresis. J Urol. 2001;166(6):2452-2455.

30. Hellstrom AL, Hanson E, Hansson S, Hjalmas K, Jodal U. Micturition habits and incontinence in 7-year-old Swedish school entrants. Eur J Pediatr. 1990;149(6):434-437

31. Bloom DA, Seeley WW, Ritchey ML, McGuire EJ. Toilet habits and continence in children: an opportunity sampling in search of normal parameters. J Urol. 1993;149(5):1087-1090.

32. Yeung CK, Godley ML, Ho CK, Ransley PG, Duffy PG, Chen CN, et al. Some new insights into bladder function in infancy. $\mathrm{Br} \mathrm{J}$ Urol. 1995;76(2):235-240.

33. Mattsson SH. Voiding frequency, volumes and intervals in healthy schoolchildren. Scand J Urol Nephrol. 1994;28(1):111 .

34. Vincent SA. Postural control of urinary incontinence. The curtsy sign. Lancet. 1966;2(7464):631-632.

35. Abrams P, Cardozo L, Fall M, Griffiths D, Rosier P, Ulmsten U, et al. The standardisation of terminology in lower urinary tract function: report from the standardisation sub-committee of the International Continence Society. Urology. 2003;61(1):37-49.

36. Schafer W, Abrams P, Liao L, Mattiasson A, Pesce F, Spangberg A et al. Good urodynamic practices: uroflowmetry, filling cystometry, and pressure-flow studies. Neurourol Urodyn. 2002;21 (3):261-274
37. Szabo L, Fegyverneki S. Maximum and average urine flow rates in normal children-the Miskolc nomograms. Br J Urol. 1995; 76(1):16-20.

38. Jansson UB, Hanson M, Hanson E, Hellstrom AL, Sillen U. Voiding pattern in healthy children 0 to 3 years old: a longitudinal study. J Urol. 2000;164(6):2050-2054.

39. Hjalmas K. Urodynamics in normal infants and children. Scand J Urol Nephrol Suppl. 1988;114:20-27.

40. Vereecken RL, Proesmans W. Urethral instability as an important element of dysfunctional voiding. J Urol. 2000;163(2):585588

41. Holmdahl G, Hanson E, Hanson M, Hellstrom AL, Hjalmas K, Sillen U. Four-hour voiding observation in healthy infants. J Urol. 1996;156(5):1809-1812.

42. Hjalmas K. Micturition in infants and children with normal lower urinary tract. A urodynamic study. Scand J Urol Nephrol. 1976;(37):1-106.

43. Koff SA. Estimating bladder capacity in children. Urology. 1983;21(3):248.

44. Mattsson S, Lindstrom S. Diuresis and voiding pattern in healthy schoolchildren. Br J Urol. 1995;76(6):783-789.

45. Rittig S, Knudsen UB, Norgaard JP, Pedersen EB, Djurhuus JC. Abnormal diurnal rhythm of plasma vasopressin and urinary output in patients with enuresis. Am J Physiol. 1989;256(4 Pt 2):F664-F671.

46. Watanabe H, Azuma Y. A proposal for a classification system of enuresis based on overnight simultaneous monitoring of electroencephalography and cystometry. Sleep. 1989;12(3):257264.

47. Aceto G, Penza R, Coccioli MS, Palumbo F, Cresta L, Cimador $\mathrm{M}$, et al. Enuresis subtypes based on nocturnal hypercalciuria: a multicenter study. J Urol. 2003;170(4 Pt 2):1670-1673.

48. Neveus T, Lackgren G, Tuvemo T, Hetta J, Hjalmas K, Stenberg A. Enuresis-background and treatment. Scand J Urol Nephrol Suppl. 2000;(206):1-44.

49. Butler RJ, Holland P. The three systems: a conceptual way of understanding nocturnal enuresis. Scand J Urol Nephrol. 2000;34(4):270-277.

50. Von Gontard A, Mauer-Mucke K, Pluck J, Berner W, Lehmkuhl G. Clinical behavioral problems in day- and night-wetting children. Pediatr Nephrol. 1999;13(8):662-667.

51. Lettgen B, von GA, Olbing H, Heiken-Lowenau C, Gaebel E, Schmitz I. Urge incontinence and voiding postponement in children: somatic and psychosocial factors. Acta Paediatr. 2002;91(9):978-984.

52 . Hellerstein S, Linebarger JS. Voiding dysfunction in pediatric patients. Clin Pediatr (Phila). 2003;42(1):43-49.

53. Combs AJ, Grafstein N, Horowitz M, Glassberg KI. Primary bladder neck dysfunction in children and adolescents I: pelvic floor electromyography lag time a new noninvasive method to screen for and monitor therapeutic response. J Urol. 2005;173(1):207-210.

54. Butler RJ. Establishment of working definitions in nocturnal enuresis. Arch Dis Child. 1991;66(2):267-271.

Correspondencia autor: Dr. R. Martínez-García.

E-mail autor: roberto.martinez@uv.es

Información artículo: Editoral 